This item was submitted to Loughborough's Research Repository by the author.

Items in Figshare are protected by copyright, with all rights reserved, unless otherwise indicated.

\title{
Practice architectures and sustainable curriculum renewal
}

PLEASE CITE THE PUBLISHED VERSION

http://dx.doi.org/10.1080/00220272.2016.1149223

\section{PUBLISHER}

(C) Taylor \& Francis (Routledge)

\section{VERSION}

AM (Accepted Manuscript)

\section{PUBLISHER STATEMENT}

This work is made available according to the conditions of the Creative Commons Attribution-NonCommercialNoDerivatives 4.0 International (CC BY-NC-ND 4.0) licence. Full details of this licence are available at: https://creativecommons.org/licenses/by-nc-nd/4.0/

\section{LICENCE}

CC BY-NC-ND 4.0

\section{REPOSITORY RECORD}

Goodyear, Victoria A., Ashley Casey, and David Kirk. 2019. "Practice Architectures and Sustainable Curriculum Renewal". figshare. https://hdl.handle.net/2134/20056. 
RUNNING HEADER: PRACTICE ARCHITECTURES

\section{Practice architectures and sustainable curriculum renewal}

Victoria A Goodyear ${ }^{\mathrm{a}^{*}}$, Ashley Casey ${ }^{\mathrm{bc}}$ and David Kirk ${ }^{\mathrm{de}}$

${ }^{a}$ School of Sport, Exercise and Rehabilitation Sciences, University of Birmingham, UK

${ }^{b}$ School of Sport, Exercise and Health Sciences, Loughborough University, UK

${ }^{c}$ Department of Physical Education and Sports Sciences, University of Limerick, Ireland

${ }^{d}$ School of Education, University of Strathclyde, UK

${ }^{e}$ School of Human Movement Studies, University of Queensland, AUS

Corresponding Author: Dr Victoria A Goodyear, School of Sport, Exercise and Rehabilitation Sciences, University of Birmingham, Edgbaston, B15 2TT, UK: 01214158397 Email: v.a.goodyear@bham.ac.uk

\section{$\underline{\text { Bibliographical Notes }}$}

Victoria Goodyear is a Lecturer in Pedagogy in the School of Sport, Exercise and Rehabilitation Sciences at the University of Birmingham, UK; email:

v.a.goodyear@bham.ac.uk. Her interests centre on curriculum change, teacher professional learning and technology.

Ashley Casey is a Lecturer in Pedagogy in the School of Sport, Exercise and Health Sciences, Loughborough University Leicestershire, UK; email: A.J.B.Casey@lboro.ac.uk. His interests centre on practitioner research and models-based practice. His most recent book is Cooperative Learning in Physical Education: A research based approach, published in paperback by Routledge in 2014.

David Kirk is the Head of School of Education at the University of Strathclyde, Glasgow, UK; email: david.kirk@strath.ac.uk. He has had a career-long interest in the teacher's role in curriculum renewal. His most recent book is Physical Education Futures, published by Routledge in 2010 


\section{PRACTICE ARCHITECTURES}

1

2

\section{Abstract}

While there are numerous pedagogical innovations and varying forms of professional learning to support change, teachers rarely move beyond the initial implementation of new ideas and policies and few innovations reach the institutionalised stage. Building on both site ontologies and situated learning in communities of practice perspectives, this paper explores the theory of practice architectures to offer a different and legitimate perspective on sustainable curriculum renewal. Specifically, a practice architecture either enables or constrains particular practice and constitutes the construction of practice from semantic (e.g. language), social (e.g. power relations), and physical (e.g. materials) spaces. Through the juxtaposition of practice architectures with an empirical illustration of longer-term pedagogical change, the paper argues that for pedagogical change to be sustained a practice architecture that relates to an innovation's intended learning outcomes and the contexts in which an innovation can be used needs to be created. Consequently, the theory of practice architectures can guide reform programmes. Curricularists can begin programmes with a pre-planned approach to assist, a) teachers' understanding of how to use an innovation, and b) the deconstruction and reconstruction of practice architectures to support an innovation's survival.

Keywords: pedagogy, curriculum renewal, pedagogical approaches, practice architecture 


\section{PRACTICE ARCHITECTURES}

\section{Introduction}

Technological innovation, economic crises, environmental and climate changes, and a whole host of other factors will continue to transform the types of knowledge and skills required in society (Apple 2014, Evans et al. 2008, Kemmis et al. 2014). Consequently, the pressures and expectations on schools and teachers to renew their practices and keep pace with the sheer reach of change is enormous (Ball 2013, Evans et al. 2008, Moore et al. 2002). Certainly, and using the context of the last three decades of state funded education in England as an example, education is caught in a cycle of innovation upon innovation with schools expected to continuously embed new approaches, policies, methods, and ideas (Ball 2013, Brown et al. 2000, Evans et al. 2008, Moore et al. 2002). The dangers of near-constant innovation are overload and teacher burnout that, in turn, result in little more than pseudo-innovation without noticeable change to curricular practices (Ball 2013, Fullan 2013, Hargreaves and Goodson 2006, Sahlberg 2011, Wallace and Priestley 2011). Consequently, teachers rarely move beyond initial implementation, and very few innovations ever reach the institutionalised stage (Fullan 2013, 2007, Hargreaves and Goodson 2006, Macdonald 2003). Fundamentally, an enduring problem that faces education is a lack of transformative and yet sustainable curriculum change.

Macdonald (2003) posited that conventional ways of thinking about curriculum innovation, ‘top-down', ‘bottom-up', and ‘partnership’ approaches, have not been helpful in assisting curriculum researchers and developers meet the challenges of near-constant curriculum reform, and therefore, we need to consider other perspectives. The purpose of this paper is to examine the theory of practice architectures and its usefulness for thinking differently about how we might sustain curriculum renewal. Consequently, this paper draws on Kemmis and colleagues’ 


\section{PRACTICE ARCHITECTURES}

conceptualisation of practice architectures (cf. Kemmis et al. 2014) to explore how this practice theory provides a new perspective on sustainable curriculum renewal. Although this paper is not primarily an empirical study, we explore the concept and further explain and present this theory by using an empirical illustration of longerterm pedagogical change. This empirical illustration (which is taken from work in a UK secondary school) allows the theory to be contextualized with longer-term change and juxtaposed with sustainable curriculum renewal.

Though practice architectures is a 'new view of practice' (Kemmis et al. 2014: 3) and has scope and potential to provide a different perspective on curriculum change, the current application of the theory to empirical data on change is limited. While Kemmis and colleagues have suggested that practice architectures transform over time, shaping and re-shaping practice, empirical examples to date have been mostly used to explain the theory and to interpret school and classroom practices. Furthermore, such understandings are predominantly associated within Kemmis and colleagues’ work in New South Wales and Queensland, Australia (Kemmis 2012, Kemmis et al. 2014) and haven’t therefore been applied outside Australia. We only have a limited sense of how the theory can be applied to different educational contexts and how it can be used to inform educational judgements about pedagogical change. By using practice architectures to explain longer-term change this paper aims to make recommendations regarding how curricularists could think differently about sustainable curriculum renewal. The research question guiding this paper is, 'how can the theory of practice architectures be used to guide our thinking about sustainable curriculum renewal?'

The next section of this paper discusses the theory of practice architectures. In this section we show how practice architectures move from a focus around an 


\section{PRACTICE ARCHITECTURES}

innovation, professional learning, and the varying reform approaches toward a consideration of how people inside (stakeholders, school leaders, teachers) and outside (curriculum developers, policy makers) schools create 'working conditions' (Kemmis and Grootenboer 2008: 61, original emphasis) that enable or constrain the use of new classroom practices. Following this initial discussion we provide a context, through an empirical illustration, to interpret and exemplify the theory. In this section we also identify the methods employed. Subsequently, empirical examples of the 'working conditions' that existed and were created are presented. In concluding this paper, we will suggest that curricularists could begin their reform programmes with a conceptualisation of the innovation, a model of professional learning and/or the approach to reform with an understanding of the 'working conditions' that will constrain and enable sustainability. Indeed, if education is to enact change and help teachers to sustain their use of innovations, a conceptualization of the 'working conditions’ could become embedded into change and reform programmes.

\section{Practice architectures}

The term practice architectures suggests that the use and development of new practices are influenced by a variety of situated and contextual factors (Kemmis 2012). This theory is, therefore, similar to other perspectives on curriculum reform since it acknowledges that the reported failures in curriculum change cannot be narrowly attributed to teachers' misinterpretations of innovations or policies (Coburn 2005, Cohen and Hill, 2008, Cohen et al. 2007, Fullan 2007, Hargreaves 1994, Spillane 1999, Spillane et al. 2002). The theory suggests that every practice enacted in classrooms is a result of a practice architecture consisting of semantic (e.g. language), social (e.g. power relations), and physical (e.g. materials) spaces (Kemmis 2012). 


\section{PRACTICE ARCHITECTURES}

Practice architectures support the idea that the use of an innovation is influenced by, the social and structural aspects of practitioners' work and their preexisting knowledge (Coburn 2005, Cohen and Hill 2008, Cohen et al. 2007, Spillane 1999, Spillane et al. 2002). Extending this previous work, practice architectures posits the interdependent nature of all of these influences, or as Kemmis et al. (2014) term them, conditions. Moreover, this theory allows for an understanding of how teachers not only make sense of new practices but how these conditions reciprocally impact the constructions of current and emerging practices. Indeed, Kemmis (2012: 886, original emphasis) suggest the practices constructed in and by the organizations, institutions and settings, and the people in them, 'hang together' to pre-figure and pre-define practice (Kemmis 2012: 886, original emphasis). Instead of implementation being primarily mediated by teachers’ personal resources (Spillane 1999, Spillane et al. 2002), both personal and external resources (for example, pupils, professional contacts and associations, and national and local policies) are interdependent and work together to construct and constitute practice.

\section{The theoretical underpinnings of practice architectures} While practice architectures have similarities with other approaches to curriculum policy implementation, the theory was built upon and combines Schatzki's (2005, 2002) interpretation of 'site ontologies' and Lave and Wenger (1991) and Wenger's (1998) discussions around ‘situated learning in communities of practice’. Practice architectures is based upon understandings of the connectedness between features of practice that exist at the site and how these features are embedded both in organizations (Schatzki 2005, 2002) and the social-cultural relations of teachers’ work (Lave and Wenger 1991, Wenger 1998). Despite offering different perspectives on practice, Kemmis and colleagues argue that Schatzki's and Lave and Wenger's views 


\section{PRACTICE ARCHITECTURES}

are dialectally related. Kemmis and Grootenboer (2008: 55-56, original emphasis) claim that we cannot merely assume the 'social world 'writes itself' onto individual persons' or that people are 'active agents 'writing themselves into’ practices'. Instead practice is constructed by and in cultural, social and material practices and thus, practice architectures are created (Kemmis and Grootenboer 2008).

\section{Interdependent arrangements of practice architectures}

According to Kemmis (2012), a practice architecture has three interdependent arrangements - cultural-discursive, material-economic, and social-political - that 'hang together' to create 'working conditions' to enable or constrain particular practices. These cultural-discursive, material-economic, and social-political arrangements, together shape existing practices and development of new practices (figure 1).

\section{[Insert figure 1 about here]}

The cultural-discursive can be understood to be the medium of language and thus occurs in a semantic space. Kemmis et al. (2014: 32) argue that we can see this feature at work in terms of 'what language or specialist discourse is appropriate for describing, interpreting, and justifying the practice'. For example, a teacher might justify their use of a teacher-led approach by using terms or phrases such as 'tighter control', 'well-managed', and 'students remain on task and are working at expected levels of proficiency’.

The social-political occurs in a social space and is the medium of power and solidarity between those with a specific investment in a particular practice. This arrangement can be seen at work in the organization's functions, rules and roles, and in the shared understandings and practical agreements a group of practitioners have about what to do in particular situations (Kemmis et al. 2014). For example, teachers 


\section{PRACTICE ARCHITECTURES}

within the same school may have shared understandings that a teacher-led approach is most effective for enabling students to learn subject content. This understanding could be further endorsed through national and school policies and curriculum documents that suggest successful lessons occur when learning is observable and when teachers manage and control an effective learning environment.

The material-economic is manifested in the physical space through activity and work. Activity and work are the resources that make practice possible. For example, this feature works by 'constraining what can be done amid the physical setups of various kinds of rooms and indoor and outdoor spaces in a school' (Kemmis et al. 2014: 32). A classroom with tables in rows and a whiteboard at the front is a good example of this arrangement. This kind of layout of a teaching space pre-determines the one-way conveyance of information, limits opportunities for dialogue between students, supports a well-managed and teacher-controlled environment and subsequently, 'hangs together' with the cultural-discursive and the social-political arrangements that also endorse knowledge and discipline.

Through the consideration of the cultural-discursive, social-political, and material-economic arrangements of practice architectures (figure 1), it seems reasonable to argue that in order for there to be new practices that are 'innovative' and for longer-term change to occur, new practice architectures need to be created. In this sense, practice architectures can help us think differently about sustainable curriculum renewal. Instead of being primarily concerned with the innovation, professional learning, or the approach to pedagogical change (i.e. 'top down', 'bottom up', or 'partnership'), practice architectures suggest that pedagogical change is either constrained or enabled by cultural, social, and material features of schools. 


\section{PRACTICE ARCHITECTURES}

\section{Setting and participants}

The empirical illustration used in this paper, physical education teachers’ voluntary uses of Cooperative Learning (Johnson and Johnson 2009), is drawn from one UK comprehensive secondary school. The school was situated in a small market town in England where the school's students were predominantly from white middleclass backgrounds. At the time of this study the UK government's Office for Standards in Education (OfSTED), who inspect schools on the quality of their educational provision, considered that the school was offering a satisfactory level of education. The grading of satisfactory meant that the school was below average in National examinations grades and required improvements to the quality of teaching and learning. Consequently, senior leaders within the school observed and assessed teachers' lessons each academic term. Assessments were based on how teachers were meeting the OfSTED teaching and learning criteria, for example, teachers were required to demonstrate how students made progress in their learning during lessons. A physical education department consisting of six qualified physical education teachers (3 male and 3 female qualified teachers) were involved in the study from which this example is drawn. The teachers varied in their age (24-37) and their professional career phases (less than two years to more than fifteen years of experience as qualified physical education teachers). Prior to their use of the innovation we are about to describe the teachers characterised their approach to physical education as being teacher-led with a skills-based sports orientated focus. In other words, teachers adopted a 'do-as-I-do’ approach to lessons where they gave instructions to the whole class and demonstrated technical skills (for example, how to pass a football or how to volley in tennis) for students to practice in decontextualized skill-based drills (for example, by students standing in lines passing the ball to one 


\section{PRACTICE ARCHITECTURES}

another or by hitting the tennis ball against the wall). Similar to the format of starter, main activity, plenary, a typical lesson structure followed warm up, skill practice, and game. The primary objective of learning in this approach is on performing skills and not on understandings or any form of social learning.

A pedagogical researcher (that we have defined elsewhere as a boundary spanner cf. Author 2013, Williams 2002) crossed her institutional boundary to work with the teachers and explore their changing practice. The boundary spanner had experience of teaching physical education through the innovation and her research explored the use of the innovation in school-based settings.

The innovation used by the teachers was Cooperative Learning. Cooperative Learning has been widely used in general education and readily applied to varying classroom contexts (Gillies and Boyle, 2005, Johnson and Johnson 2009, Kyndt et al. 2013). However, despite the dynamic and adaptable nature of this innovation, in physical education Cooperative Learning is still considered to be a new practice and has not been widely adopted or used over a sustained period of time (Author 2015). In physical education Cooperative Learning is described as a type of student-centred pedagogical approach that promotes the achievement of physical, cognitive, social, and affective learning outcomes (Dyson and Casey 2012). Rather than teaching and learning being solely based on skills and techniques, students are encouraged to develop their skills and techniques (physical) alongside, for example, their understanding (cognitive), their interpersonal skills (social), and their self-esteem (affective). The focus of lessons is around students being active, social, and creative learners where students are interdependent to learn in their small structured heterogeneous groups (Dyson et al. 2004). The teacher's role is less direct and based 


\section{PRACTICE ARCHITECTURES}

upon encouraging students to construct their own understandings with the support of their peers (Dyson and Casey 2012, Gillies and Boyle 2005).

The distinctive features of Cooperative Learning that support the achievement of the multiple learning outcomes are five separate elements (Author 2015). These elements are positioned as a pentagonal scaffold that guides and authenticates teachers' use of Cooperative Learning (Dyson and Casey 2012). The five elements are, positive interdependence, individual accountability, group processing, promotive face-to-face interaction, and small group and interpersonal skills.

\section{Data gathering}

Ethical approval was sought prior to data gathering. Data were drawn from the first academic year of the study and at a time when the teachers began using Cooperative Learning i.e. October 2011-July 2012. During this time each teacher had selected at least one class to teach through Cooperative Learning. The classes involved were all single sex and ranged from year 7 (age 11-12) to year 10 (age 1415). Over the course of the year all teachers taught at least five separate units of work (6-12 lessons of one hour each) to these classes using Cooperative Learning. Data were gathered through video recorded lessons, interviews, the boundary spanner's field journal, and from teaching and learning documents that existed in the department.

The first and last lesson of each unit was video recorded. These lessons were analysed using the Cooperative Learning Validation Tool (CLVT), which involved a systematic process of note taking to validate the use of Cooperative Learning and to determine whether the learning outcomes reported on were a result of the authentic use of the innovation (Author 2015). For example, the boundary spanner noted how the teachers had used the distinctive features of Cooperative Learning (for example, 


\section{PRACTICE ARCHITECTURES}

group processing) and reported on the type of learning that was observed (for example, cognitive learning).

Semi-structured interviews, each lasting between 5-20 minutes, were

conducted both before and after each of the video recorded lessons. These pre- and post- lesson interviews provided an interpretation of the teacher's plans for a lesson and their immediate interpretations of the lesson. Semi-structured interviews also took place before and after each unit. These unit interviews lasted between 20-50 minutes and focussed on each teacher's unit goals and their experiences of using the innovation across a series of lessons. At the end of the academic year semi-structured interviews, which lasted between 30-60 minutes, were conducted with each teacher to understand their longer-term use and engagement with Cooperative Learning. All interviews were recorded and transcribed.

Throughout the year data were gathered from the boundary spanner's field journal and the department's documents for teaching and learning. Entries were made to an electronic field journal immediately following each of the boundary spanner's visits to the school and were focussed on events, informal discussions (i.e. those not recorded and which took place in, for example, the department's office), and the boundary spanner's interpretations of the teachers' changing practice. Departmental documents i.e. the programme of study (i.e. the planned content for units in a specific time period), the schemes of work (i.e. learning outcomes for units and lesson-bylesson content), and teachers' plans and resources for the lessons that were video recorded were also collected and analysed.

Data analysis

In keeping with the research question 'how can the theory of practice architectures be used to guide our thinking about sustainable curriculum renewal?' 


\section{PRACTICE ARCHITECTURES}

data were analysed inductively using typological analysis (Goetz and LeCompte 1984, Hatch 2002) and constant comparison (Glaser and Strauss 1967). This involved placing the data into three categories: cultural-discursive, social-political, and material-economic. With data placed in three categories analytical induction (Goetz and LeCompte 1984) took place within each category. The data were coded and placed in a series of emerging categories and subcategories. This process identified the features of each of the cultural-discursive, social-political, and material-economic arrangements. We then identified commonalities across each of the three categories and identified features of each of the arrangements that 'hung together'. From this process the dominant features of practice architectures that constructed and constituted practice within each category were identified. Each arrangement was then mapped over time to identify when changes to practice occurred and if changes were similar across the three arrangements.

To increase the validity of the empirical illustration the peer examination strategy was used throughout (Gall et al. 1996, Merriam 1995). This involved the authors member-checking, noting how items were placed into the three categories and how features of practice within each category were coded. Data were moved between different categories and placed under different codes until the authors reached an agreement. In reporting on the findings of this analysis below it is important to note that the identities of the teachers have been masked through the use of pseudonyms.

\section{The changing 'working conditions'}

In this section we show the initial 'working conditions' for practice that existed in our study and then the new conditions for practice that were created, which supported teachers' uses of Cooperative Learning. We do this by exploring the cultural-discursive, material-economic, and social-political arrangements of practice 


\section{PRACTICE ARCHITECTURES}

architectures (figure 1) and show how they changed over the course of the academic year.

This section shows that initially, a practice architecture existed that endorsed a teacher-led, skills-based, sports-orientated approach. The language used to interpret and justify practice reflected 'leading’, skills, and sports. This cultural-discursive arrangement 'hung together' with the curriculum documents that existed (and thus the shared expectations for teaching and learning) and the school's expectations for practice (social-political arrangement). A teacher-led, skills-based, and sportsorientated approach was further endorsed by the facilities (i.e. the vast space of the sports hall), large class sizes, and the equipment or physical spaces that brought heightened safety implications (material-economic). Therefore, and similar to other school subjects, despite teachers being willing and enthused by the use of an innovation (Cooperative Learning), a dominant cultural-discursive justification for a teacher-led approach, teachers' interpretations of department expectations and the criteria for practice from, for example, OfSTED (social-political), and the classroom size, large class sizes and the materials and resources for lessons (material-economic) 'hang together' to create 'working conditions' that constrained teachers use of new practices.

After a period of approximately six months (or three separate units of activity), new working conditions were being created that were more coherent in relation to Cooperative Learning. In cultural-discursive terms, the teachers positioned learning in multiple domains (physical, cognitive, social, and affective) as being important and justified students working interdependently in small groups with the teacher being less direct as an effective pedagogical approach. In social-political terms and in keeping with this change in language, the department created new shared 


\section{PRACTICE ARCHITECTURES}

expectations for teaching and learning that mirrored the innovation's intentions and the department now saw the innovation as capable of meeting governmental and school expectations for teaching and learning. However, while new culturaldiscursive and social-political arrangements were created, new material-economic arrangements were not. Certainly it would be unrealistic to suggest that the creation of new physical spaces to facilitate the use of Cooperative Learning would be remotely viable. They did, however, adapt their uses of the physical space to better facilitate the practise of Cooperative Learning.

Before discussing the three arrangements it is important to acknowledge that, similar to the J-curve of implementation (where attitudes and understandings get more confused before an improvement in practice occurs (Bunderson 2003)), the development of new working conditions was a messy process (Cook 2009). Following the initial use of the innovation, and at a time when it was being implemented within the pre-existing conditions for practice, we suggest that the teachers moved into a 'messy area' (Cook 2009: 281) of practice change. Consistent with Cook’s (2009) interpretation, this was a time when multiple viewpoints about practice existed that conflicted and contrasted with each other. However, this 'messy area', as Cook (2009) suggests, acted as a precursor for the creation of something new and enabled new practices to be revealed, developed, and articulated. Indeed, when practitioners are 'within the mess' (Cook 2009: 286, original emphasis), they begin to clarify what is known and what is nearly known. Practitioners move backwards and forwards between old and new practices until new working conditions are developed.

\section{Cultural-discursive: the semantic space}

The specialist discourse the teachers initially brought into their classrooms reflected a sport-focused, skills-based, teacher-led approach. Teachers prioritised and 


\section{PRACTICE ARCHITECTURES}

legitimised effective teaching and learning as being focussed on the physical learning domain, specifically, skills for sport. Indeed, when they began using the innovation, it was seen as 'working in different sports', a way of 'teaching the skills of sport' and 'preparing them [the pupils] to play sport'. The teacher-led approach was justified and perceived as an effective way of teaching different sports. This justification can be understood from the following comment from a teacher who had more than 15 years' experience of teaching physical education.

I have never given a lesson away as such.... physical education has always been teacher leads the practice, teacher leads the differentiation, teacher leads the progress, and the next steps.... when I teach basketball it is always watch and focus, focus on this part, what am I doing, focus on that part, two, or three teaching points to discuss. I thought with Cooperative Learning nah sod it get them doing it, which may have been the downfall (Sean, Post-Lesson Interview, January 2012).

His comment shows that he felt a teacher-led approach had been an inherent part of his teaching of physical education. When using Cooperative Learning, and in attempting to take less of a teacher-led role in the classroom, he suggested that his perception of a lack of student progress was a result of Cooperative Learning. Over the course of the year, the 'centrality' of a sport-focused, skills-based, teacher-led approach moved to the periphery of the teachers' justifications for their practice. Although other factors may have played a role, this change in teachers' perception most evidently occurred as a result of students' positive responses to the innovation. As an experienced teacher, Sean suggested the feedback from the students confirmed that a different approach was effective for his practice.

The feedback from students was very positive...listening to the students and them saying that they enjoyed the method of delivery as opposed to what they had experienced in the past...I like the structure, the feedback from the students is good, so I guess my focus is now on developing it (Post-Unit Interview, March 2012).

However, and similar to Spillane et al. (2002), it took more than a single 


\section{PRACTICE ARCHITECTURES}

discrepant event to challenge teachers' interpretations of their practice. Certainly, and reflective of the 'messy area' (Cook 2009), the teachers' perceptions of their practice moved backwards and forwards between the innovation and their previously dominant practices of sport, skills, and a teacher-led approach. Yet, the teachers' perception of and enthusiasm for using the innovation did not decline and it was the repeated positive feedback from their students and observations of their students learning that contributed to a change in their perception of their role in the teaching and learning process, and subsequently, the language that was used to justify their practice. For example, following an understanding that the innovation was effective for his practice, in the first lesson of the next unit Sean suggested that 'they would find it really difficult to do without my input’ (Pre-Lesson Interview, April 2012). However, at the end of this lesson his perception of Cooperative Learning was changing. In response to his observations of his students' learning and engagement during the lesson he said that it went 'surprisingly well...they are still engaged and they performed very well...it has certainly opened my eyes to teaching Athletics' (Post-Lesson Interview, April 2012). Thus, this teacher was beginning to perceive that his students did not require a teacher-led approach in order to learn.

At a time when most teachers had taught approximately three separate units of activity, most teachers drew on their observations of students' responses to the innovation to construct an understanding that moving from a teacher-led approach and focussing on multiple learning outcomes and the holistic development of the child were important. The teachers began to consider that their previously dominant sportorientated curriculum was ineffective, and perhaps incapable of meeting some of the social learning outcomes that were now valued. The language used reflected students' ability to listen and communicate with each other (social learning) and be creative 


\section{PRACTICE ARCHITECTURES}

(cognitive learning), where these outcomes were seen as more beneficial than a sportcentred curriculum focussed on merely skills and techniques (physical learning). Indeed, as the teachers used Cooperative Learning and observed and listened to their students' responses, they were beginning to see that catering for multiple learning outcomes was more effective for students' development and that Cooperative Learning was an effective way of meeting these multiple learning outcomes. You know even though sport hasn't been at the centre, they have learnt to teach each other, they have learnt to listen to each other, and they have learnt to actually create and challenge each other, and I think having a more holistic development of the child, rather than having a sport-centred curriculum, has definitely been more beneficial. (Sophie, Post-Unit Interview, May 2012)

Multiple learning outcomes were seen as beneficial because they were noted to be vital learning outcomes that could contribute to preparing young people for their own cultural engagement in society. Significantly, a direct association was made between student learning in the social and cognitive domains when the teachers moved from their predominant use of a teacher-led approach. This change can be seen in the comment below. A new vocabulary for describing practice emerged that reflected providing students with 'independence' rather than the 'teacher leads the practice'. 'Independence' was then seen as an effective way of supporting ‘cooperation’ (social learning) and enabling students to ‘think divergently’ (cognitive learning). Cooperative Learning became further legitimised, as a curriculum practice, since such 'independence’ and social and cognitive learning were not seen as possible within their previous use of a teacher-led approach.

It was the kind of independence you give the kids and without that independence in their lives and their ability to think kind of divergently away from their groups and kind of the cooperation element fulfils a lot more needs rather than being spoon fed and therefore they are going to develop a lot more as a rounded person and that skill set and that skill base will aid them in multiple curriculum areas rather than your bog standard physical education lesson where they are given a demonstration, they are told what to do and how to do it and they then perform the task (Aaron, Post-Unit Interview, July 
PRACTICE ARCHITECTURES 2012).

\section{Social-political: the social space}

Shared rules and expectations for practice based on sports, skills and, techniques existed within the department. Certainly, in examining the programme of study and the schemes of work, the content and focus of units and lessons were around sports and skills. The programme of study pre-determined that teachers would teach a minimum of five different six-lesson units focusing on different types of sport. The schemes of work also pre-determined that the focus of learning would be skillbased. The learning outcomes drawn from the netball scheme of work exemplify the emphasis on the skills and techniques for sport: 'pupils will be able to consolidate basic skills in skill practices and full-sized games focusing on accuracy, quality and control of techniques...'.

For the first units taught, the department's teaching and learning documents were used as a primary resource for choosing the content of lessons. The teachers drew on the programme of study and the schemes of work to plan for their lessons and units. Indeed, the department had a shared understanding that the content within these curriculum documents was appropriate for planning units and lessons. As the field notes show below, the teachers used these documents as a way of constructing their use of Cooperative Learning.

She [Vanessa] began by looking at the whole year....and what areas of range and content [activities or sports] she was on...it seemed she needed a basis of where to go [in the planning of lessons] and she needed the content of the unit to be able to adapt it to Cooperative Learning (Field Journal, December 2011).

Beyond the programme of study and the curriculum guides that the teachers used to construct their initial lessons and units, the school's rules and socially shared expectations for teaching and learning influenced the teachers' use of the new practice. This influence on practice was particularly evident during each teacher's 


\section{PRACTICE ARCHITECTURES}

routine lesson observations by senior leaders in the school. These lesson observations focused on each teacher meeting specific criteria related to OfSTED’s framework for practice. One of the criteria stated that teachers needed to show that students made significant progress in their learning during a lesson. Subsequently, the teachers claimed that they couldn't use Cooperative Learning for the duration of the one hour lesson; 'I only used that for certain bits of it I didn’t do it for the whole lesson it is quite hard to do it for a whole lesson observation' (Claire, Post-Lesson Interview, February 2012). However, the teachers were not frustrated by the need to adhere to the school's expectations. Instead it was almost accepted that Cooperative Learning could not fulfil all of the school's teaching and learning expectations. The following field notes further this point and highlight that in order for the teachers to show students were meeting the skill based learning outcome, a teacher-led approach was an acceptable way of responding to the expectation of showing progress. In this way, the school's rules for teaching and learning that was a result of their adherence to OfSTED became a socially shared way of teaching lessons within the department.

One of the success criteria was the students would be able to adopt the ready position [skill], therefore when they weren't applying this and this was a small part of her outcomes, she had to pause the whole class and make sure that they were doing it. If she had gone around the groups and asked partners what they were doing and how they needed to be doing it then this would have taken the 20mins of her lesson observation and potentially the students wouldn't have been meeting the criteria (Field Journal, April 2012).

While challenges existed in the using Cooperative Learning within the school's expectations for practice, at a time period when teachers began to value the effectiveness of the innovation (that was evidenced in their on-going use of new language to describe what they and their students were doing in lessons, as discussed in cultural-discursive condition), a shared understanding within the department was emerging that Cooperative Learning was an effective curriculum practice. Indeed, 


\section{PRACTICE ARCHITECTURES}

discussions about Cooperative Learning became an agenda point within the formal

scheduled meetings with teachers sharing units and plans for lessons.

The physical education department had a meeting yesterday and shared their units that they had planned to teach of Cooperative Learning. This was one of the first times the department had scheduled time in a meeting and have chosen to speak about Cooperative Learning rather than it being enforced by me (Field Journal, April 2012).

The teachers and department's belief that Cooperative Learning adhered to and could meet the OfSTED criteria emerged into these departmental meetings. Prior to the next scheduled lesson observations by senior leaders in the school the assistant curriculum leader in the department suggested that 'the inclusion of the OfSTED criteria into Cooperative Learning should be the focus of all the department's next units, if they were going to be able to use it' (Field Journal, May 2012). This 'was something she felt she would share in the next department meeting' (Field Journal, May 2012). Consequently, and as evidenced through all teachers' willingness to modify their approach, the department reached a shared agreement that they would begin to refine their use of Cooperative Learning. For example, instead of using a teacher-led approach that contrasted with the intentions of Cooperative Learning, one teacher used additional questions during group processing (a distinctive feature of Cooperative Learning) to allow students to communicate their progress.

I have added a third question so what went well in your team, what does your team need to do to do better and I was always focussing on as a team not as the practise, and my third one is how have you made progress in this lesson and how do you know, which is for OfSTED and is making sure that they can state how they think they have made progress and how they think and why they think they have made progress. (Vanessa, Post-lesson Interview, May 2012).

However, while the department had reached a shared agreement that they would attempt to adapt their practice to meet the school's teaching and learning expectations, for some teachers this process of change was problematic. Although all 


\section{PRACTICE ARCHITECTURES}

teachers engaged with the process of adaptation, an understanding amongst all members of the department that Cooperative Learning was capable of meeting the school expectations did not immediately occur. For example, some teachers 'felt that the OfSTED criteria didn't match the expectations of student-centred lessons' (Field Journal, June 2012). It was only through the repeated attempts to change and align the use of the Cooperative Learning elements with OfSTED criteria and through sharing plans and resources within department meetings, that a shared agreement emerged that Cooperative Learning was capable of meeting the school-based teaching and learning expectations. Certainly, every member of the department chose to teach through Cooperative Learning as part of the routine school observations toward the end of the academic year. The fear and resistance to the use of Cooperative Learning in formal lesson observations disappeared, and it was noted that, 'all the teachers seemed to be quite up for it and getting an external opinion of Cooperative Learning but to also see how it matches with Ofsted criteria’ (Field Journal, June 2012). With all lessons subsequently graded as good or outstanding, Cooperative Learning was increasingly becoming a socially shared and accepted way of teaching and learning within the department and within the school. Where previously practice was constrained and the teachers adopted a teacher-led approach to show student progress, the teachers felt that were able to modify their approach in a way that allowed them to demonstrate progress.

I thought it was less teacher-led...every single person improved, every person progressed, some more than others and all the OfSTED criteria was met (Aaron, Post-lesson Interview, July 2012).

Around the same time, when the teachers began to modify their use of the innovation to include OfSTED criteria, the teachers also restructured their lessons and the curriculum. This was largely in response to the frustrations caused by whole 


\section{PRACTICE ARCHITECTURES}

school events (for example, school trips or whole school themed events), the weather, and teachers' extraneous pastoral responsibilities in the school that caused lessons to be cancelled (i.e. the class was either absent, students were taught by a cover supervisor, or three classes (approximately 90 students) were required to be taught in one space and, as a result, the use of Cooperative Learning wasn't seen as possible). For example, 'during an informal conversation with Aaron, he commented on how he just 'gets going on something and then bam you have got to change to a different unit' (Field Journal, February 2012). Following a period (most evidently through the second and third units taught) where teachers were required to cancel their lessons and units were shortened to less than six lessons teachers' attitudes changed. They made the decision in future units that 'they didn't want to cut the units short' (Field Journal, May 2012). The school-based restrictions to their practice seemed to influence the teachers to not only maintain the six lesson units but to now extend the unit length and begin choosing their own content (or topics). In some cases, this meant that the teachers created new unit outcomes and objectives and units that lasted eight, ten and in some cases twelve lessons.

Toward the end of the year, the innovation was seen to be part of the culture of the department. Extending the discussions in formal meetings, as one teacher said 'there's always an open conversation about it [the innovation] and sharing of experience' (Vanessa, End of Academic Year Interview). Moreover, the department created new schemes of work and resources for Cooperative Learning: 'we are redesigning our schemes of work... and we are having a Cooperative Learning box... setting up a central resource for each of the sports through Cooperative Learning (Vanessa, End of Academic Year Interview). While it was evident that there was still a focus on sport, it had moved to the periphery within the department and their 


\section{PRACTICE ARCHITECTURES}

individual and collective pedagogical approach. Subsequently Cooperative Learning's inherent focus on multiple learning domains (physical, social, cognitive, and affective) became the primary focus of each unit's scheme of work. In this way, the department overcame the school's expectations by finding ways to incorporate OfSTED criteria into their lessons and they had created new teaching and learning documents within the department that were coherent with both OfSTED and the features, aims, and objectives of the innovation.

\section{Material-economic: the physical space}

The pre-planned programme of study that teachers followed and determined their activity or sport for their first few units taught (as discussed within the socialpolitical arrangement) also pre-determined the physical space where lessons would take place. 'Hanging together’ with the social-political arrangement and a sportsorientated focussed programme of study, most lessons were pre-determined to take place with classes of approximately thirty students over one hour and in the sports halls, on the sports fields, or on multi-purpose surfaces, such as the Astroturfs. Large spaces and class sizes, coupled with the time constraint of a one-hour lesson, proved to be problematic for the teachers in using Cooperative Learning. For example, ‘during his [Aaron’s] Football lesson on the Astro[turf] he seemed frustrated... he said he just wanted to bring them in and tell them what to do and how to do it' (Field Journal, February 2012). Indeed, for many teachers it was noted that they wanted to ‘control the structure of the lesson’ (Field Journal, January 2012), something that was possible in the teacher-led approach but that was challenging when students worked in small teams on different activities spread out in a field or a sports hall. On a number of occasions, the teachers brought the students in from various areas of the hall, field or Astroturf for a whole class discussion. These whole 


\section{PRACTICE ARCHITECTURES}

class discussions, as the observation notes on one lesson show, allowed the teachers to stick to their pre-planned timings of the tasks in their one hour lessons where the class discussions most often occurred at three time points: after the warm up, after the skill practice, and after the game (or the starter, main activity, plenary).

Sophie controls the structure of the lesson by telling students when and what they should be doing by bringing the whole class into the middle of the [Football] pitch. For example, after the warm up she tells them that they should be moving on to the skill part of the lesson and that the coaches and equipment manager should be setting up the drills, she then brings the class in and tells them its time to move onto the game. (CLVT, January 2012)

Similar perhaps to lessons that take place in Science laboratories, the perceived need to adopt a teacher-led approach was also particularly prevalent when learners were required to use certain equipment that had enhanced safety implications (for example, Javelins, vaulting boxes, or trampolines) and in physical spaces that had specific safety regulations (for example, the swimming pool). By using an example from swimming the influence of the pre-determined safety regulations on practice can be better understood. The comment below reflects one teacher's decision to only use Cooperative Learning in swimming when he taught classes of less than thirty students. This teacher considered that, due to safety considerations, allowing thirty students to work in small groups in the swimming pool was not possible. This constraint on where and with what classes the innovation could be used was further exacerbated by the duration of swimming lessons. Due to changing time and the use of the swimming pool, which was in an off-site facility (i.e. within a public leisure centre) that required students to travel to the facility within their one hour lesson, the teacher felt that students would have less time to be active in the pool and develop their skills. As a result, this teacher only ever used Cooperative Learning in swimming when working with a class of fifteen students or less. Boundary Spanner: why have you chosen to use this class? 


\section{PRACTICE ARCHITECTURES}

Liam: Due to the swimming pool environment and the timings of 20/40 minutes. If larger groups, it will be difficult to have as much active time in the pool to develop and analyse their techniques... and for safety reasons if I have individuals working in the pool I need to know where they are all the time. (Liam, Pre-Unit Interview, December 2011)

While the teachers could not change the physical spaces or the safety

regulations (and by this we mean they could not create or construct a new sports hall, buy new fields, multi-sports surface, or develop new equipment and implement new safety regulations) to facilitate their use of Cooperative Learning, they were able to reconstruct how these physical spaces were used. Although the sports hall was seen as a space that had previously been used for traditional sports, this space was restructured during the year to allow students to work in their groups together to create (as an example of cognitive and social learning) their own sports and games. Indeed, and at a similar time to when the teachers' perceptions of their role in the teaching and learning process and the language used to justify their practice was changing (as discussed in cultural-discursive), the teachers reduced their amount of control in lessons by adopting a role of active supervision. As one teacher suggested, 'students had the space to create their own Frisbee golf courses....it was absolutely manic because there were Frisbees flying everywhere' (Sophie, Post-Unit Interview, May 2012). Although some teachers felt that they needed to 'make the activities more structured as while they [the students] were creative it could become quite disruptive (Liam, Post-Unit Interview, May 2012), what became ‘thinkable’ during lessons changed.

A change in what was 'thinkable' seemed to occur as a result of the teachers' observations and the understanding gained from their experiences of using the innovation. Indeed, an understanding developed that students required more space and time to learn in multiple learning domains and be able to work together independently 


\section{PRACTICE ARCHITECTURES}

662

663

664

665

666

667

668

669

670

671

672

673

674

675

676

677

678

679

680

681

682

683

684

685

686

687

688

689

690

691

692

693

694

(key changes in language seen in the cultural-discursive arrangement) of the teacher's

direct instructions. It was considered that time and space allowed students to learn

interdependently in the social and cognitive domains with the teacher supporting

learning only when students required it:

When they are practising you need to give them a space to practise, the time to talk to each other and the time to work things out for themselves and learn from their mistakes... what I have realised is that I don't need to be with the learning teams all of the time, sometimes its just standing back and watching and then facilitating the learning when the students need your support. (Sophie, End of Academic Year Interview)

A change in what was 'thinkable' in the physical spaces was also reflected in

teachers' practice with reference to the perceived safety constraints of using the innovation with certain equipment and with large class sizes. Where previously they avoided situations, such as the case in swimming, they began to modify their approach and used the innovation in these physical contexts. As the comment below reflects, teachers started to consider that they now only needed to control the safety (in a teacher-led way) for small parts of lessons or in parts of the units when there were specific safety concerns. The teachers placed an emphasis on the interdependent nature of learning (as a reflection of the cultural-discursive arrangement) and it was much more a case of ensuring students understood the safety regulations to allow students to learn from each other 'safely'.

I think there are certain aspects where you have to come in and take over and safety and stuff, like Javelin... but when you do that and let them go away they are absolutely fine. So I do think there are aspects where you do have to take over and do that teacher role but then give them chance to go out and do it for themselves. It would only be in terms of safety or explaining what they need to do for that unit and what to do to start with. (Claire, Post-Unit Interview, July 2012).

Enabling students to work in new spaces when there were safety concerns was one of the last of the new working conditions to be developed. Despite attempts to afford students more ownership and responsibility, it was a need for safety that often 


\section{PRACTICE ARCHITECTURES}

695

696

697

698

699

700

701

702

703

704

705

706

707

708

709

710

711

712

713

714

715

716

717

718

719

caused teachers to revert back to a teacher-led approach. As Claire suggested, even

within the units toward the end of the academic year, 'I spent ages talking and

controlling the safety at the beginning of lessons' (End of Academic Year Interview)

\section{Discussion}

To keep pace with the sheer expectation of change, schools and teachers have been presented with a near constant stream of innovations to better align practice with contemporary economic and social challenges (Ball 2013, Brown et al. 2000, Evans et al. 2008, Moore et al. 2002). However, despite the pressures and expectations on schools and teachers to renew their practices year-on-year, the near-constant state of innovation has resulted in teacher burnout, with limited sustained change to curricular practices (Ball 2013, Fullan 2013, Hargreaves and Goodson 2006, Sahlberg 2011, Wallace and Priestley 2011). Indeed, the opportunities for sustainable curriculum renewal, that would see teachers develop and adapt their practices over time, have been sparse (Fullan 2013, 2007, Hargreaves and Goodson 2006, Macdonald 2003).

Certainly, conventional ways of thinking about curriculum reform, 'top-down', 'bottom up', and 'partnership', have not been capable of meeting the challenges of supporting longer-term change (Macdonald 2003). Therefore, and as we identified at the beginning of this paper, there is a need to consider other perspectives in our quest for sustainable curriculum renewal.

The purpose of this paper has been to examine the theory of practice architectures and its usefulness in understanding curriculum renewal. Through an empirical illustration we have shown that the creation of new working conditions (that aligned with an innovation's intentions) contributed to longer-term pedagogical change. Therefore, in order for teachers to sustain their use of an innovation and for it to become capable of being institutionalized a practice architecture that relates to an 


\section{PRACTICE ARCHITECTURES}

innovation's intended learning outcomes and the pedagogical circumstances for an innovation's use needs to be created. We argue that this theory and concept offers a different perspective on sustainable curriculum renewal and has the scope and potential to influence change and reform programmes. This paper will now critically explore how practice architectures could be used and further explored by curricularists to facilitate sustainable curriculum renewal. It seems important to emphasise firstly that the diverse and varying professional learning and the differing reform approaches (i.e. bottom up, top down, or partnership) approaches should not be excluded or replaced by approaching change through practice architectures. Moreover, the theory of practice architectures compliments but yet extends policy implementation approaches and/or models (Coburn 2005, Cohen and Hill 2008, Cohen et al. 2007, Spillane 1999, Spillane et al. 2002) by focussing on the interdependent nature of cultural, social and material conditions and how these, together, not only influence interpretation of innovations but an innovation's longer-term use. Therefore, we argue that the concept of practice architectures should work with these approaches and be used to inform reform approaches.

In particular, the concept of practice architectures provides an alternative starting point for thinking differently about educational change. From the very onset, pedagogical change can be approached with an identification of what is needed for an innovation's longer-term use. Curricularists who introduce an innovation could begin by identifying a practice architecture and, specifically, the language, the materials, and the socially shared rules and routines that could 'hang together' and pertain to the innovation's longer-term existence. From this end point, curricularists can begin to develop programmes with a pre-planned approach to assist a) teachers’ understanding 


\section{PRACTICE ARCHITECTURES} 767 is required.

of how to use an innovation, and b) the deconstruction and reconstruction of practices to ensure an innovation's survival.

While curricularists could introduce programmes and support the development of new practices, it is also worth noting that practitioners could embark on pedagogical change by engaging with the theory of practice architectures. Firstly, practitioners could examine their beliefs and interpretations of practice (culturallydiscursive), the materials and resources available (material-economic) and the rules and routines that exist in their context (social-political), exploring how these relate to their current practices. Following this, practitioners could identify what language (culturally-discursive), materials and resources (material-economic), and rules and routines (social-political) need to be in place to use and sustain an innovation. Thus, practitioners could approach curriculum change and sustainable curriculum renewal through a critical consideration of how and why certain practices have been sustained (deconstruction) and how and why new practices could be sustained (reconstruction). It was identified in this paper that students' responses to the innovation and a department's collective investment in change supported a modification in the 'working conditions'. In this sense, experience using an innovation and engaging in processes, such as participatory action research, that involve constructing understandings with colleagues and students in the local context (Kemmis and McTaggart 2008), could support the deconstruction and reconstruction of new practices. A more comprehensive understanding, however, of the contextual needs and the professional learning that aids the development of new practice architectures

Although a practice architecture that pertains to an innovation's use can be identified, by referring back to the original theoretical perspectives of site ontologies 


\section{PRACTICE ARCHITECTURES}

770 (Schatzki 2005) and situated learning (Lave and Wenger 1991, Wenger 1998), the

771 pre-existing 'working conditions' may vary between sites and between communities

772 of practitioners. Indeed, through their positioning of practice as being constructed in

773 and by cultural, social and material practices Kemmis et al. (2014) have

774 fundamentally acknowledged that practices between sites and communities differ.

775 Although those constructed outside of the site may have somewhat homogenous

776

777 expectations - such as curriculum guides and OfSTED expectations - it is how these practices are interpreted and mediated in the school, between practitioners, and in the classroom, that determines how they are used. For example, and in the broadest sense, how do practices constructed outside the school and brought into the site vary between Free Schools (or independent schools (Sweden) or Charter Schools (USA)), and state schools (Hatcher 2011)? Moreover, how curricular or pedagogical strategies are interpreted may vary between groups of teachers and between individuals (Brown et al. 2000, Cohen and Hill, 2008, Cohen et al. 2007, Spillane 1999, Spillane et al. 2002).

It is important to acknowledge that practice architectures are transformative and will change over time depending on how an individual or group of individuals choose to accept or reject new practices that come into being (Kemmis 2012). Thus the process of deconstruction and reconstruction is dependent on how the current dominant and valued practices have been constructed in and by cultural, social, and material practices. Consequently, although further research which explores the deconstruction and reconstruction of a practice architecture may provide valuable insights into how to facilitate sustainable curriculum renewal, we emphasise here that the process may vary between sites, between teachers, and may change over time. 


\section{PRACTICE ARCHITECTURES}

In this paper we presented a practice architecture that pertained to one innovation or pedagogical approach and we showed how the creation of a practice architecture supported sustainable curriculum renewal. Thus, the key message emerging from this study, and the contribution to literature on curriculum development and change, is that practice architectures offers a new perspective and approach for curricularists and professional learning providers to support sustainable curriculum renewal. Moreover, the empirical data has sought to provide new insights into how teachers might engage with on-going curriculum development by using practice architectures to frame their curriculum programmes.

\section{Conclusion}

In concluding this paper, we reemphasise that sustainable curriculum renewal is a central problem in education (Fullan 2013, Hargreaves and Goodson 2006, Sahlberg, 2011, Wallace and Priestley 2011). With few examples of longer-term change, practice architectures presents itself as a theory and a conceptual approach to guide innovations and reform approaches. Despite this, there are a number of limitations in this study and to the theory of practice architectures that should be acknowledged.

The empirical illustration used in this paper was based on a small sample of teachers and in the context of one school and one curriculum subject. In addition to limiting generalizability, sustainable curriculum renewal could have occurred because of a design experiment (Fishman and Krajcik 2003). In other words, we created the 'perfect' conditions for sustainable curriculum renewal to occur and for sustainable curriculum renewal to then be explained through practice architectures. It is also worth noting that the teachers in this study voluntary chose to develop their curriculum around Cooperative Learning. Many proposed curricula changes in 


\section{PRACTICE ARCHITECTURES}

education, however, are not teacher-initiated, with policy often requiring teachers to change their practices and embed new curricula or standards (Spillane et al., 2002). While other theories have proved particularly useful in explaining why teachers engage and reject policy change (Coburn 2005, Cohen and Hill, 2000, Cohen et al. 2007, Spillane 1999, Spillane et al. 2002), resistance could have been minimal in this study. As a result, the extensive body of research that indicates how the alignment of policy with teachers' beliefs impact on the intensity of change (Cohen et al. 2007, Spillane et al., 2002), suggests that teacher beliefs may play a more pivotal role in sustainable curriculum renewal than was portrayed in this study. Finally, when aligning practice architectures to sustainable curriculum renewal, this perspective does not account for how teachers' knowledge of an innovation, or how the complexity of an innovation or policy, may effect teachers' approach to sustainable curriculum renewal (Fullan 2007, Cohen and Hill, 2000, Cohen et al. 2007). As a result, we suggest that teachers' knowledge and an innovation's complexity should be considered as key influencers of sustainable curriculum renewal.

The limitations that we have identified highlight that a further empirical understanding of practice architectures is required. Evidence from large sample sizes and from diverse educational contexts would ensure that the theory is a viable and credible approach to sustainable curriculum renewal. Moreover, and to further understand the usefulness of the theory, we need to a) empirically understand how practice architectures can be used to frame sustainable curriculum renewal, b) to understand how they can be used to guide a curriculum programme, and c) to understand how teachers develop their use of pedagogical approaches over time once practice architectures have been constructed to facilitate their sustainability. 


\section{References}

Author 2015, 2013

Apple, M.W. (2014) Official knowledge: democratic education in a conservative age (New York: Routledge).

Ball, S.J. (2013) The education debate (Great Britain: The Policy Press).

Brown, M., Bibby, T. and Johnson, D.C. (2000) Turning our attention from the what to the how: the national numeracy strategy. British Educational Research Journal, 26 (4), 457--471.

Bunderson, C.V. (2003) Four frameworks for viewing blended learning cases: comments and critique. The Quarterly Review of Distance Education, 4 (3), $279-288$.

Coburn, C.E. (2005) Shaping teacher sensemaking: school leaders and the enactment of reading policy. Educational Policy, 19 (3), 476--509.

Cohen, D.K., Morfitt, S.L. and Goldin, S. (2007) Policy and practice: the dilemma. American Journal of Education, 113 (4), 515--548.

Cook, T. (2009) The purpose of mess in action research: building rigour through a messy turn. Educational Action Research, 17 (2), 277-291.

Dyson, B. and Casey, A. (eds) (2012) Cooperative Learning in physical education: A research-based approach (London: Routledge).

Dyson, B., Griffin, L.L. and Hastie, P. (2004) Sport education, tactical games, and cooperative learning: Theoretical and pedagogical considerations. Quest, 56 (2), 226--240.

Evans, J., Rich, E., Allwood, R. and Davies, B. (2008) Body pedagogies, P/policy, health and gender. British Educational Research Journal, 34(3), 387-402.

Fishman, B.J. and Krajcik, J.S. (2003) What does it mean to create sustainable science curriculum innovations? A commentary. Science Education, 87 (4), 564-573.

Fullan, M. (2013) Stratosphere: integrating technology, pedagogy and change knowledge (Toronto, Ontario: Pearson).

Fullan, M. (2007) The new meaning of educational change (London: Routledge).

Gall, M.D., Borg, W.R. and Gall, J.P. (1996) Educational Research: an introduction, $6^{\text {th }}$ edition (London: Longman).

Gillies, R.M. and Boyle, M. (2005) Teachers’ scaffolding behaviours during cooperative learning. Asia-Pacific Journal of Teacher Education, 33 (3), 243-259.

Glaser, B.G. and Straus, A.L. (1967) The discovery of grounded theory: strategies for qualitative research (Chicago, IL: Aldine)

Goetz, B.G. and LeCompte, M.D. (1984) Ethnography and qualitative design in educational research (San Diego, CA: Academic Press)

Hargreaves, A. and Goodson, I. (2006) Educational change over time? The sustainability and non-sustainability of three decades of secondary school change and continuity. Educational Administration Quarterly, 42 (1), 3--41.

Hatcher, R. (2011) The conservative-liberal democrat coalition government's "free schools” in England. Educational Review, 63 (4), 485--503.

Hattie, J. (2009) Visible learning: a synthesis of over 800 meta-analyses relating to achievement (Oxon: Routledge).

Johnson, D. and Johnson, R. (2009) Joining together: group theory and group skills (Upper Saddle River: N.J. Pearson).

Kemmis, S. (2012) Researching educational praxis: spectator and participant perspectives. British Educational Research Journal, 38 (6), 885--905. 
Kemmis, S. and Grootenboer, P. (2008) Situating praxis in practice: practice architectures and the cultural, social and material conditions for practice. In S. Kemmis and T.J. Smith (eds), Enabling praxis: challenges for education (The Netherlands: Sense Publishers), 37--62.

Kemmis, S. and McTaggart, R. (2008) Participatory action research: communicative action and the public sphere. In N.K. Denzin and Y.S. Lincoln (eds), Strategies of Qualitative Inquiry (Thounsands Oaks, CA: Sage), 271--330.

Kemmis, S., Wilkinson, J., Edwards-Groves, C., Hardy, I., Grootenboer, P. and Bristol, L. (2014) Changing practices, changing education (London: Springer).

Kirk, D. (2013) Educational value and models-based practice in physical education. Educational Theory and Philosophy, i First Article

Kyndt, E., Raes, E., Lismont, B., Timmers, F., Cascallar, E. and Dochy, F. (2013) A meta-analysis of the effects of face-to-face cooperative learning. Do recent studies falsify or verify earlier findings?. Educational Research Review, 10, 133--149.

Lave, J. and Wenger, E. (1991) Situated learning: legitimate peripheral participation (New York: Cambridge University Press).

Macdonald, D. (2003) Curriculum change and the post-modern world: is the school curriculum-reform movement an anachronism?. Journal of Curriculum Studies, 35 (2), 139--149.

Merriam, S.B. (1995) What can you tell from an $\mathrm{N}$ of 1 ? Issues of validity and reliability in qualitative research. PACE Journal of Lifelong Learning, 4, 51-60.

Metzler, M. (2011) Instructional models for physical education $3^{\text {rd }}$ edition (Arizona: Holcomb Hathway).

Moore, A., Edwards, A., Halpin, D. and George, R. (2002) Compliance, resistance and pragmatism: the (re)construction of schoolteacher identities in a period of insensitive educational reform. British Educational Research Journal, 28 (4), 551--565.

Sahlberg, P. (2011) Finish lessons: what can the world learn from educational change in Finland? (Amsterdam: Teachers College Press).

Schatzki, T.R. (2005) The sites of organizations. Organization Studies 26 (3), 465-484.

Schatzki, T. (2002) The site of the social: a philosophical account of the constitution of social life and change (Pennsylvania: University of Pennsylvania Press).

Spillane, J. P. (1999) External reform initiatives and teachers' efforts to reconstruct their practice: the mediating role of teachers' zones of enactment. Journal of Curriculum Studies, 31 (2), 143-175.

Spillane, J.P., Reiser, B.J. and Reimer, T. (2002) Policy implementation and cognition: reframing and refocusing implementation research. Review of Educational Research, 72 (3), 387-431.

Wallace, C.S. and Priestley, M. (2011) Teacher beliefs and the mediation of curriculum innovation in Scotland: a socio-cultural perspective on professional development and change. Journal of Curriculum Studies, 43 (3), 357--381.

Wenger, E. (1998) Communities of practice: learning, meaning and identity (Cambridge: Cambridge University Press).

Williams, P.M. (2002) The competent boundary spanner. Public Administration, 80, 103--124. 


\section{PRACTICE ARCHITECTURES}

943

944 